the personal equation when searching for a dependable and intelligent history as in cases 2 and 3 . The patient's replies honestly given undoubtedly smeared the issue in each of the last two cases.

This small series of reports is brought forward, each presenting a special feature and each a particular problem, and for that reason they possibly possess some value. They must not be considered as having been reported with any idea of depleting such an inexhaustable subject. That they are fortuitous, I am ready to admit; otherwise I would not have deemed them worthy of your attention.

\title{
THE PHENOMENAL VISUAL ACUITIES OF THE EUROPEAN CHIMNEY SWALLOW
}

BY

\author{
S. Holth \\ osLo
}

IN Casey A. Wood's “The Fundus Oculi of Birds," Chicago, The Lakeside Press, 1917, the author states that Hirundo rustica has a trimacular fundus; one nasal fovea for monomacular vision for far distances and two temporal foveae for bimacular vision in short distances. In the chromolithograph after Arthur W. Head's painting ( $1 c$, Plate L) only two of the three foveae are visible; the most external temporal fovea is outside the area of the reproduction.

In July, 1913, I convinced myself that Hirundo rustica has phenomenally sharp vision both for far and short distances. In

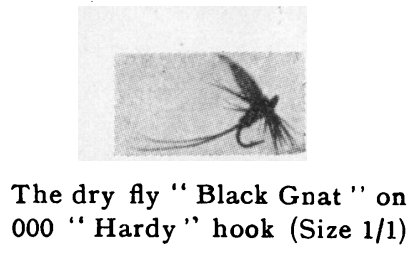

bright sunshine the swallows hunted tiny insects-mostly the common midge, Culex pipiens-very high up in the air and often in full speed changed the direction in acute angles. Suddenly one of them from at least 20 metres height became interested in my little dry fly "Black Gnat" on 000 " Hardy" hook during trout fishing and rushed down to it; but in about one metre's distance from the dry fly the swallow stopped abruptly with the 
wings transversally; he observed with his temporal foveae perhaps the little hook-if in profile as in the illustration-but certainly the hairfine (0.006) undyed transparent drawn gut cast, which he had never seen connected with any living insect; with his nasal fovea he had monocularly detected the fly itself from at least the distance of 20 metres.

I admired the animal, but found it safest in the future never to fish with the dry fly when swallows are hunting in the landscape.

\section{ANNOTATION}

\section{The Combined Treatment in Glaucoma}

In common with most other scientific journals, the Brit. Jl. of Ophthal. does not accept responsibility for the views of authors of original communications. Our present number contains an article on the treatment of glaucoma by Dr. G. Herbert Burnham, which may possibly not be entirely acceptable to many of our readers. The proposition that many cases of primary glaucoma can be overcome by non-operative treatment may seem rather revolutionary; but it must be remembered that, although glaucoma as a sign can be put into the water-tight compartment of raised tension, the causes of the condition are probably manifold, and in practice no two cases may be quite the same. Dr. Burnham in his paper does not submit a very large number of cases relieved by this method of treatment, but this may be a kindly desire on his part to save our space. The fact remains that he is a very senior member of the ophthalmic fraternity, an old house-surgeon at Moorfields and one of the few surviving original members of the Ophthalmological Society of the United Kingdom still in practice. He is convinced of the beneficial effect of his method of treatment in such cases, and it is only fair that he should be allowed to state views founded upon long experience. As our ideas about the cause of primary glaucoma are being revolutionised by the cumulative effect of research work in many lands, it is reasonable to hope that at no distant date we may understand the underlying principles of this condition; and, when the cause is known the methods of treatment may have to be varied. With a view to the future, therefore, we are publishing the paper that our readers may become acquainted with a treatment, of which little has so far been heard in this country. 